\title{
ironXS: high-school screening for hereditary haemochromatosis is acceptable and feasible
}

\author{
Martin B Delatycki ${ }^{\star, 1,2,3,8}$, Michelle Wolthuizen ${ }^{1,8}$, Veronica Collins ${ }^{1}$, Elizabeth Varley ${ }^{1}$, Joanna Craven ${ }^{1}$, \\ Katrina J Allen ${ }^{1,2,4}$, Lyle C Gurrin ${ }^{5}$, Maryanne Aitken ${ }^{1,2}$, M Kaye Trembath ${ }^{1}$, Lyndal Bond ${ }^{6}$, \\ Gabrielle R Wilson $^{1}$, Sarah EM Stephenson ${ }^{1,2}$, Ivan Macciocca ${ }^{7}$, Chriselle Hickerton ${ }^{1}$, Paul J Lockhart ${ }^{1,2}$ \\ and Sylvia A Metcalfe $e^{1,2}$
}

As the results of the Human Genome Project are realised, screening for genetic mutations that predispose to preventable disease is becoming increasingly possible. How and where such screening should best be offered are critical, unanswered questions. This study aimed to assess the acceptability and feasibility of genetic screening for preventable disease, using the model of hereditary haemochromatosis, in high-school students. Screening was offered for the HFE C282Y substitution to 17638 students. Questionnaires were administered at the time of screening (Q1) and approximately 1 month after results were communicated (Q2). Outcomes assessed were uptake of screening, change in scores of validated anxiety, affect and health perception scales from Q1 to Q2, knowledge and iron indices in C282Y homozygous individuals. A total of 5757 (32.6\%) students had screening and 28 C282Y-homozygous individuals ( 1 in 206) were identified, and none of the 27 individuals who had iron indices measures had significant iron overload. There was no significant change in measures of anxiety, affect or health perception in $\mathrm{C} 282 \mathrm{Y}$ homozygous or non-homozygous individuals. Over $86 \%$ of students answered each of five knowledge questions correctly at Q1. Genetic population-based screening for a preventable disease can be offered in schools in a way that results in minimal morbidity for those identified at high risk of disease. The results of this study are not only relevant for haemochromatosis, but for other genetic markers of preventable disease such as those for cardiovascular disease and cancer. European Journal of Human Genetics (2012) 20, 505-509; doi:10.1038/ejhg.2011.247; published online 11 January 2012

Keywords: genetic screening; adolescent health; haemochromatosis; informed consent; high school

\section{INTRODUCTION}

As the results of the human genome project are realised, the ability to screen individuals for genetic alterations that predispose to preventable disease has increased exponentially. Genetic screening is likely to significantly impact the prevention of a range of disorders, including cancer ${ }^{1}$ and cardiovascular disease ${ }^{2}$ particularly if implemented at the population level as knowledge about genetic impact on diseases and risks associated with population screening processes are better understood.

Genetic screening for carrier status of heterozygous mutations for recessive diseases such as Tay Sachs disease and $\beta$-thalassaemia has been available since the 1970s. The incidence of these conditions in screened populations has been markedly decreased. ${ }^{3}$ By contrast, there is little population genetic screening for risk of disease in the individual being screened. Hereditary haemochromatosis (HH; OMIM 235200), a disorder of iron overload that can result in liver cirrhosis and hepatocellular carcinoma, is an ideal condition to understand further issues regarding population-based genetic screening processes, as the genetics of the disease are well understood. ${ }^{4}$ Importantly, $\mathrm{HH}$ is common with over two million individuals homozygous for the HFE $845 \mathrm{G} \rightarrow \mathrm{A}$ transition (that results in the $\mathrm{C} 282 \mathrm{Y}$ amino acid substitution), the commonest mutation that results in $\mathrm{HH}$, and thus at risk of disease, in the United States and Europe alone. Controversy exists regarding the penetrance of disease in those homozygous for this mutation. A large cross-sectional study reported a penetrance of less than $1 \%{ }^{5}$ although the methodology of this study was criticised. ${ }^{6-8}$ We conducted a longitudinal study of disease in 142 individuals homozygous for this mutation and found a minimum penetrance for iron overload-related disease of $28.4 \%$ for male subjects and $1.2 \%$ for female subjects. ${ }^{4} \mathrm{HH}$ is both preventable and treatable by the simple procedure of venesection.

Various models for population-based genetic screening have been proposed. These include the primary healthcare setting, ${ }^{9}$ the workplace, ${ }^{10}$ as part of newborn screening ${ }^{11}$ and more recently high schools. ${ }^{12}$ High-school screening for carrier status for recessive diseases such as Tay Sachs disease and cystic fibrosis, for future reproductive risk, has been conducted since the 1970s. ${ }^{13,14}$ High schools may be an ideal setting for successful population screening programmes; however, there have been no large-scale studies of high-school genetic screening programmes for preventable disease in the screened individual.

We aimed to assess whether population-based genetic screening for preventable disease using $\mathrm{HH}$ as the model is acceptable and feasible in the high-school setting. We hypothesised that screening would not result

${ }^{1}$ Bruce Lefroy Centre for Genetic Health Research, Murdoch Childrens Research Institute, Parkville, Victoria, Australia; ${ }^{2}$ Department of Paediatrics, The University of Melbourne, Royal Children's Hospital, Parkville, Victoria, Australia; ${ }^{3}$ Department of Clinical Genetics, Austin Health, Heidelberg West, Victoria, Australia; ${ }^{4}$ Department of Gastroenterology, Royal Children's Hospital, Parkville, Victoria, Australia; ${ }^{5}$ Centre for MEGA Epidemiology, School of Population Health, University of Melbourne, Parkville, Victoria, Australia; ${ }^{6}$ MRC Social and Public Health Sciences Unit, Glasgow, UK; ${ }^{7}$ Genetic Health Services Victoria, Parkville, Victoria, Australia

${ }^{*}$ Correspondence: Professor MB Delatycki, Bruce Lefroy Centre for Genetic Health Research, Murdoch Childrens Research Institute, Flemington Road, Parkville, Victoria 3052, Australia. Tel: +61 39496 4355; Fax: +61 38341 6390; E-mail: martin.delatycki@ghsv.org.au

8These authors contributed equally to this work

Received 13 July 2011; revised 3 November 2011; accepted 24 November 2011; published online 11 January 2012 
in psychological morbidity and that screened individuals would take steps to prevent iron overload. We adopted a programme evaluation approach ${ }^{15}$ that included five stages: (1) negotiation and planning, comprising needs assessment and stakeholder input; ${ }^{15}$ (2) programme development and formal evaluation; ${ }^{16}$ (3) programme implementation; (4) evaluation of short-term outcomes; and (5) evaluation of long-term outcomes. Here we present data in relation to evaluation questions from stages 3 and 4, based on assessment of 5757-screened students.

\section{MATERIALS AND METHODS}

The methods of subject recruitment and data collection have been described in detail previously and are summarised in Figure $1 .{ }^{16}$ Briefly, students at randomly selected schools that represented the four main school types (urban and rural, government and non-government schools) were shown a purposely designed educational DVD. Following this, they were provided with a parent information pack to take home. Approximately 2 weeks later, students with parental consent, who also provided their own consent, were screened for the HFE $845 \mathrm{G} \rightarrow$ A transition by a self-administered cheek brush test. Approval for this study was granted by the Ethics in Human Research Committee of the Department of Human Services, Victoria, Australia. An agreement was reached with the Australian insurance industry peak body that ensured that any person found to be homozygous for the HFE $845 \mathrm{G} \rightarrow$ A transition, but without evidence of organ damage would not be disadvantaged in obtaining insurance. ${ }^{17}$

There were three possible outcomes of screening: individuals homozygous (henceforth termed YY), heterozygous (CY) and homozygous wild type (CC) for the C282Y substitution. Screening results were provided to parents and students through their home contact details. Those found to be $\mathrm{CY}$ or CC received a letter to their home address stating that the student is at very low risk of developing HH. YY individuals and their parents were advised of the result by telephone by a genetic counsellor. A blood test was arranged at that time to confirm the genetic test result and to measure iron indices. They were also invited to attend a clinic to have a formal clinical assessment and further genetic counselling. The genetic counselling included information about the genetic and clinical aspects of $\mathrm{HH}$ that included the option of becoming a blood donor, the penetrance of disease, based on the results of our previous study ${ }^{4}$ including the different risks for male and female subjects and risk to and availability of genetic testing for family members.

\section{Assessment tools}

At the time of screening, students were asked to complete a baseline questionnaire (Q1), which can be accessed at http://www.ironxs.com.au/questionnaire/.
Some parents/students provided consent for only the questionnaire component of the study. ${ }^{16} \mathrm{~A}$ follow-up questionnaire (Q2) was sent 1 month after receiving the test results to all YY and CY individuals, and to approximately one in seven randomly selected CC individuals. The questionnaires included previously validated or tested items: (1) demographic details (recorded in Q1); (2) the General Health Perception sub-scale of the Medical Outcomes Survey, SF-36 that measures self-assessed health status; ${ }^{18}$ (3) the state component of the short form of the Spielberger State-Trait Anxiety Inventory, a measure of transitory anxiety; ${ }^{19,20}$ (4) the Positive and Negative Affect Schedule (PANAS); ${ }^{21,22}$ and (5) the intrusion sub-scale of the Impact of Event Scale, a tool that measures psychological response to a particular stressor as manifested by the extent of intrusive thoughts. ${ }^{23}$ In this case, the stressor was being at risk of developing $\mathrm{HH}$. Items 2 to 4 , above, were measured both in Q1 and Q2, whereas item 5 was only measured in Q2.

Understanding of four key concepts presented in the pre-test education programme was measured with five multiple-choice questions described previously. ${ }^{16}$ The concepts tested were knowledge of: (1) the aetiology of $\mathrm{HH}$; (2) the symptoms of $\mathrm{HH}$; (3) prevention and treatment for those at high risk of $\mathrm{HH}$; and (4) penetrance of the $\mathrm{C} 282 \mathrm{Y}$ substitution.

All YY individuals were invited to attend a follow-up clinic within 1 month of receiving their result by telephone. A standardised clinical evaluation directed towards complications of $\mathrm{HH}$ was performed by one of two study physicians (KJA, MBD).

\section{Statistical analysis}

Data were analysed using STATA IC/10.0. (StataCorp, College Station, TX, USA). Descriptive statistics were used to describe the sample in terms of demographic, clinical and psychological characteristics. Total numbers within categories differ slightly for each variable due to missing data for some questions. Statistical significance of differences in mean levels of continuous variables between YY and non-YY (ie, CY and CC) individuals was assessed by independent sample $t$-tests. The statistical significance of group differences in categorical variables was assessed using $\chi^{2}$-tests of association with Yates correction. Statistical significance of mean differences between baseline and follow-up scores for anxiety and general health perception was assessed using paired $t$-tests. A $P$-value $<0.05$ was considered to be statistically significant.

\section{RESULTS}

\section{The screening process}

A total of 17638 students from 62 schools were offered screening, of whom 5757 (32.6\%) had genetic testing. The uptake was significantly

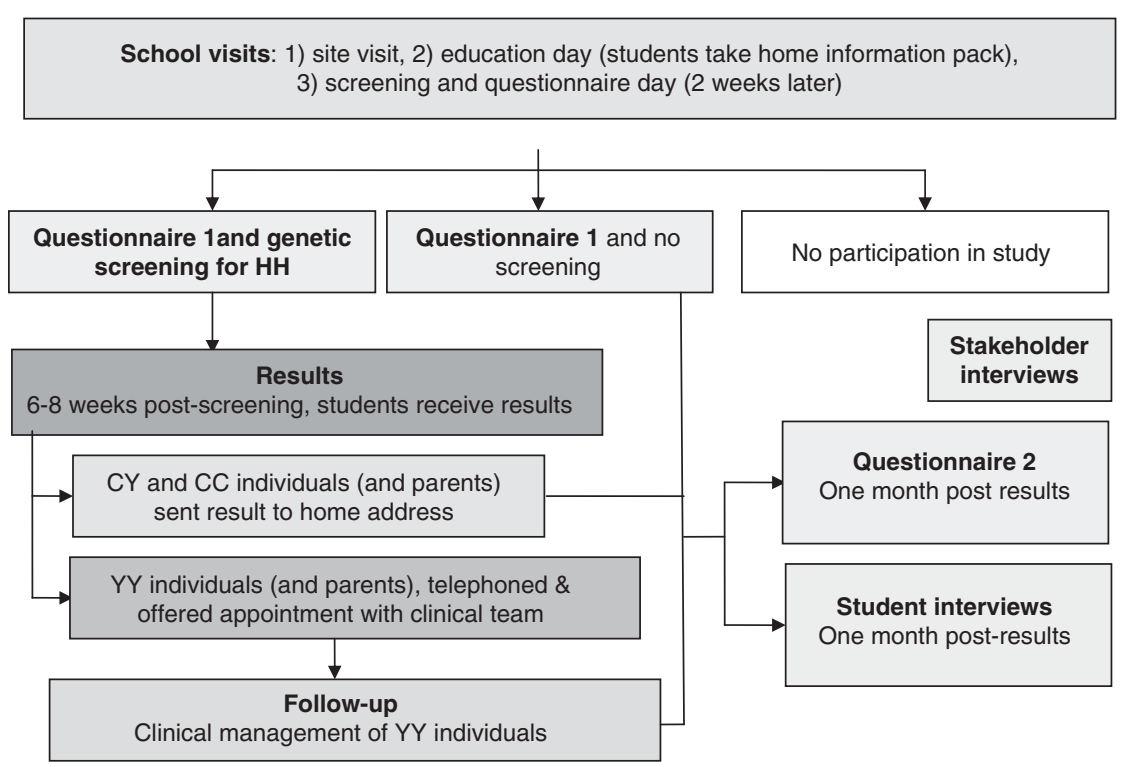

Figure 1 The process of the described program. 
Table 1 The number of schools and students offered screening in government and non-government schools and the uptake of screening

\begin{tabular}{lccc}
\hline & Non-government & Government & Total \\
\hline Schools & $32^{\mathrm{a}}$ & 30 & 62 \\
Students offered screening & 9187 & 8451 & 17638 \\
Number screened & 3484 & 2273 & 5757 \\
Percentage screened & $37.9^{\mathrm{b}}$ & $26.9^{\mathrm{b}}$ & 32.6 \\
\hline aA total of 13 schools participated in two separate years. & & \\
bThe difference in uptake between non-government and government schools was significant, \\
$P<0.001$.
\end{tabular}

Table 2 The frequency of the HFE C282Y substitution in screened students and the characteristics of participants, based on HFE genotype

\begin{tabular}{lccccr}
\hline $\begin{array}{l}\text { Result } \\
\text { group }\end{array}$ & Frequency & $\begin{array}{l}\text { Relative } \\
\text { freq (\%) }\end{array}$ & Ratio & Male: female & $\begin{array}{c}\text { Northern } \\
\text { European (\%) }\end{array}$ \\
\hline YY & 28 & 0.5 & 1 in 206 & $14: 14$ & $21(75)$ \\
CY & 586 & 10.2 & 1 in 10 & $254: 332$ & $484(83)$ \\
CC & 5143 & 89.3 & & $2246: 2897$ & $3269(64)$ \\
Total & 5757 & 100 & & $2514: 3243$ & \\
\hline
\end{tabular}

higher in non-government (37.9\%) than government (26.9\%) schools $\left(\chi^{2}=243, P<0.001\right.$; Table 1$)$. There was a significant negative correlation between the size of the group of students offered screening and the uptake (Supplementary Figure 1). That is, on average, the smaller the group at the education session, the higher the percentage of students who had screening.

The mean age of participants was $15.6(\mathrm{SD}=0.7)$ years (range 14-18). Twenty-eight students were identified as YY (1 in 206) and 586 students were identified as CY ( 1 in 10; Table 2). The gender distribution of the students in the study and the proportion with selfreported Northern European ethnic origin are also shown in Table 2. CY and YY individuals were more likely to report being of Northern European ancestry $(82.2 \%)$ compared with CC individuals (63.6\%; $\left.\chi^{2}=84.8, P<0.001\right)$.

\section{Questionnaire outcomes}

The proportion of participants who returned Q2 was 28/28 (100\%) for YY individuals, 461/570 (80.9\%) for CY individuals and 644/807 (79.8\%) for CC individuals.

The results of a number of measures of psychological status (Spielberger State-Trait Anxiety Inventory, SF36, PANAS-positive and PANAS-negative) conducted at the time of testing (Q1) were compared with the same measures completed after the students were aware of their genetic status (Q2). There was no significant difference in any of the measures before testing compared with after receiving results for any of the measures for YY or non-YY individuals (Table 3). The impact of events scale did not show any significant negative impact of the test result for either YY or non-YY individuals as evidenced by the low mean scores. The vast majority of YY (93\%) and non-YY individuals (89\%) were pleased they had testing. Almost all YY (93\%) and most non-YY individuals (72\%) remembered the number of copies of the $\mathrm{C} 282 \mathrm{Y}$ substitution that they were found to have.

\section{HH morbidity}

All 28 YY individuals had normal examination of abdomen and joints without signs of chronic liver disease. Twenty-seven of the
Table 3 Measures before testing (Q1) and 1 month after receiving test results (Q2) for $Y Y$ and non-YY individuals

\begin{tabular}{|c|c|c|c|}
\hline & $Y Y(\mathrm{n}=28)$ & $\begin{array}{l}\text { Non-YY } \\
(\mathrm{n}=1105)\end{array}$ & $P^{a}$ \\
\hline \multicolumn{4}{|l|}{ SF-36 scores ${ }^{b}$} \\
\hline Q1 & 70.5 (7.9) & $67.2(13.7)$ & 0.21 \\
\hline Q2 & $72.6(9.8)$ & $69.9(13.8)$ & 0.32 \\
\hline$P^{c}$ & 0.33 & $<0.001$ & \\
\hline \multicolumn{4}{|l|}{ STAI state anxiety scores ${ }^{\mathrm{d}}$} \\
\hline Q1 & $31.2(8.3)$ & $33.0(10.5)$ & 0.35 \\
\hline Q2 & $30.7(8.1)$ & $33.7(11.5)$ & 0.17 \\
\hline$P^{\mathrm{c}}$ & 0.80 & 0.053 & \\
\hline \multicolumn{4}{|l|}{ PANASP scores ${ }^{\mathrm{e}}$} \\
\hline Q1 & $31.8(7.3)$ & $32.3(7.2)$ & 0.69 \\
\hline Q2 & $31.5(8.4)$ & $32.9(7.6)$ & 0.35 \\
\hline$P^{c}$ & 0.84 & 0.019 & \\
\hline \multicolumn{4}{|l|}{ PANASN scores ${ }^{\mathrm{e}}$} \\
\hline Q1 & $16.6(5.6)$ & $18.2(6.5)$ & 0.20 \\
\hline Q2 & $15.4(4.9)$ & $18.4(6.6)$ & 0.16 \\
\hline$P^{\mathrm{c}}$ & 0.30 & 0.42 & \\
\hline IES scores ${ }^{f}$ & $1.1(2.3)$ & $1.5(3.8)$ & 0.58 \\
\hline $\begin{array}{l}\text { Number who remembered result (copy number) } \\
\text { correctly }\end{array}$ & $26(93 \%)$ & $793(72 \%)$ & 0.016 \\
\hline Number pleased to have had test & $26(93 \%)$ & $981(89 \%)$ & 0.26 \\
\hline
\end{tabular}

Abbreviations: IES, Impact of Event Scale; PNASN, Positive and Negative Affect Schedulenegative; PNASP, PNAS-positive; STAI, State-Trait Anxiety Inventory. Data are mean (SD) or number of individuals (\%) unless otherwise stated.

aComparison of mean score for YY versus non-YY individuals by two sample $t$-test. SF36 scores range from 0 to 100 , with a higher score indicating better perceived health status.

cPaired $t$-test comparing scores before (Q1) and after (Q2) testing.

dSTAI scores range from 20 to 80 and are comparable to scores from the full form of the STAI. A higher score indicates greater anxiety.

eThe PANAS scale comprises 20 items (10 items comprise the PANASP and 10 items the PANASN subscales) with a five-point scale for each item ranging from very slightly (1) to extremely (5). The two subscales therefore have a scoring range of $10-50$, where a higher score indicates greater affect.

IIES scores (measured in Q2 only) range from 0 to 35 with a higher score indicating a higher stress response. A score of 9 or higher has been suggested to be clinically significant in a study of the impact of genetic testing. ${ }^{35}$

twenty-eight YY individuals had iron indices assessed, following the identification of their genetic status (Supplementary Table 1). Transferrin saturation was elevated in $7 / 13(53.8 \%)$ male individuals and $5 / 14(35.7 \%)$ female individuals $\left(\chi^{2}=0.90, P=0.34\right)$. Only one male individual $(320 \mu \mathrm{g} / \mathrm{l})$ and one female individual $(261 \mu \mathrm{g} / \mathrm{l})$ had raised serum ferritin, and in both cases, it was only marginally raised above the upper limit of normal for gender $(300 \mu \mathrm{g} / \mathrm{l}$ for male individuals and $200 \mu \mathrm{g} / \mathrm{l}$ for female individuals).

\section{Knowledge}

At baseline (Q1), more than $86 \%$ of students correctly answered each of the five knowledge questions (Supplementary Table 2). One month after results were received, YY individuals maintained high knowledge levels for all but one question, although non-YY individuals had a significant reduction in knowledge for three of the five questions.

\section{Reasons for choosing to be screened}

Students were asked in Q1, the reason they chose to have screening. The most commonly cited reason was that they wished to find out 
their risk of $\mathrm{HH}(62.2 \%)$. Less common responses were that their parents wanted them to have screening $(13.3 \%)$ and that it was easy $(9.8 \%)$ or free $(9.7 \%)$ to have testing. Less than $1 \%$ indicated that the decisions of their friends/peers influenced their participation.

\section{DISCUSSION}

Genetic screening for a preventable disease in a school setting was both acceptable and feasible as evidenced by no adverse psychological consequences, very high knowledge levels and high levels of satisfaction with the process of screening amongst those who participated. Using a two-step consent process requiring both written parental and student consent, participation was lower than for previous one-step school-based programmes, ${ }^{24}$ suggesting that consenting processes need to be efficient to facilitate optimal uptake.

The strengths of this study are that this is the single largest population-based study to date of genetic screening in schools. The schools were population-representative and as such, results can be readily translatable to the general population. High questionnaire return rates minimise responder bias, and the large number of YY individuals identified enabled us to be confident that the study is sufficiently powered to identify any major negative consequences.

The major limitation of this study is low uptake by study participants, which is most likely due to the two-step consenting process. We believe uptake would be higher if only written student consent was required for the following reasons. In an attitudinal study conducted before the current study, $68 \%$ of students indicated that they definitely or probably would have $\mathrm{HH}$ screening were it to be offered. ${ }^{12}$ Furthermore, there was a more than $95 \%$ uptake of screening for Tay Sachs disease and related conditions, in high schools where written parental consent was not required. ${ }^{24}$ In addition, when we offered $\mathrm{HH}$ screening as part of a workplace study, $90 \%$ of university students who were offered screening chose to be screened. ${ }^{10}$ The university students were on average $2-3$ years older than the students in the current cohort.

Unfortunately, we were unable to ask students the reasons for why they did not have screening, as this required parental consent, which we did not have for the vast majority of students in this category. To explore this issue further, we sought to undertake a study to assess screening uptake where parents could opt-out of allowing their children to participate, but without the requirement of written parental consent; however, the Ethics Committee did not allow this to take place.

A major concern that has been raised in relation to screening for $\mathrm{HH}$ is that individuals found to be at high risk will be adversely affected psychologically. ${ }^{25}$ One study found some negative emotional responses following the diagnosis of $\mathrm{HH}$ by population screening, ${ }^{26,27}$ whereas others have not. ${ }^{10,28,29}$ Psychological morbidity from the screening process in the current study was assessed by administration of validated questionnaires before and after students were made aware of their genetic status. This enabled change in status to be assessed. There was no evidence that psychological morbidity results from students learning that they are at risk of HH. This is likely because morbidity from $\mathrm{HH}$ is preventable if the individual maintains normal iron indices by venesection. The students received pre-test information by a purpose-designed DVD and then YY individuals had information provided face-to-face by a physician and genetic counsellor after receiving their result. The fact that $\mathrm{HH}$ does not result in disease in all YY individuals and is preventable was reinforced a number of times, both in the pretest education and in the post-result consultation. We found similar results to this in a workplace $\mathrm{HH}$ screening study. ${ }^{10}$
In this study, knowledge levels were very high following one-to-many education, indicating that in terms of understanding, consent was informed. More than $86 \%$ of students answered each of the knowledge questions correctly at baseline. This is higher than was the case for the workplace study we conducted previously in which questions related to the genetic concepts of penetrance and genetic heterogeneity were answered incorrectly $>25 \%$ more often than in the current study. ${ }^{30}$ One possible reason for the differences is the fact that in the current study, the educational DVD was much more targeted to the audience compared to the workplace study. Another possible reason is that school students are in an educational environment and so may be more open to complex concepts than individuals in the workplace. Finally, some of the students had studied genetics and so may have been aware of these concepts before the screening programme visiting their school.

A concern with offering screening to high-school students is that peer pressure will unduly influence decision-making. ${ }^{31}$ Less than $1 \%$ of students indicated that their friends having screening was the major influence in their decision to have screening. Although this does not completely alleviate concerns in relation to this issue, it provides significant reassurance. About $13 \%$ of students noted that parental wishes were most important in the decision to be screened. This indicates that for a minority of students, the decision to be screened was not entirely their own, although it does not mean that those students had screening against their wishes.

The issue of whether community screening for $\mathrm{HH}$ should be introduced is a controversial one. ${ }^{32,33}$ There are many factors that need to be considered before such a programme is introduced. These include the burden of disease, whether or not there is an acceptable preventive intervention and health economic considerations to name some. For $\mathrm{HH}$, a major issue in relation to whether community screening should be introduced is the disease penetrance. ${ }^{4,5}$ Our recent longitudinal study indicates that penetrance in YY male subjects is considerable, but is low in YY female subjects. ${ }^{4}$ These issues are important not only in deciding whether to introduce screening in the community, but also for individuals in deciding whether they wish to have screening. For the current study, insurance concerns were largely negated by the agreement reached with the Australian insurance industry. ${ }^{17}$ Similar agreements do not exist in other jurisdictions and so would need to be addressed before $\mathrm{HH}$ screening programmes could be introduced, albeit that insurance discrimination in $\mathrm{HH}$ appears to be rare. ${ }^{34}$

In conclusion, this study has demonstrated that genetic populationbased screening for a preventable disease can be offered in a schoolbased setting in a way that results in minimal morbidity for those identified as being at high risk of disease. Our study found that young people are able to make informed decisions about whether or not they wish to have screening and have a high level of satisfaction with the screening process. The results of this study are not only relevant for $\mathrm{HH}$, but for other genetic markers of preventable disease such as those for cardiovascular disease and cancer.

\section{CONFLICT OF INTEREST}

The authors declare no conflict of interest.

\section{ACKNOWLEDGEMENTS}

This study was funded by the National Health and Medical Research Council (491224) and the Jack Brockhoff Foundation. MBD is a National Health and Medical Research Council (Australia) Practitioner Fellow. KJA is Viertel Senior Medical Research Fellow. 
1 Calzone K, Wattendorf D, Dunn BK: The application of genetics and genomics to cancer prevention. Semin Oncol 2010; 37: 407-418.

2 Humphries SE, Drenos F, Ken-Dror G, Talmud PJ: Coronary heart disease risk prediction in the era of genome-wide association studies: current status and what the future holds. Circulation 2010; 121: 2235-2248.

3 Delatycki MB: Population screening for reproductive risk for single gene disorders in Australia: now and the future. Twin Res Hum Genet 2008; 11: 422-430.

4 Allen KJ, Gurrin LC, Constantine CC et al: Iron-overload-related disease in HFE hereditary hemochromatosis. N Engl J Med 2008; 358: 221-230.

5 Beutler E, Felitti VJ, Koziol JA, Ho NJ, Gelbart T: Penetrance of 845G-> A (C282Y) HFE hereditary haemochromatosis mutation in the USA. Lancet 2002; 359: 211-218.

6 Allen KJ, Warner B, Delatycki MB: Clinical haemochromatosis in HFE mutation carriers. Lancet 2002; 360: 412-413,

7 Cox T, Rochette J, Camaschella C, Walker A, Robson K: Clinical haemochromatosis in HFE mutation carriers. Lancet 2002; 360: 412

8 Poullis A, Moodie SJ, Maxwell JD: Clinical haemochromatosis in HFE mutation carriers. Lancet 2002; 360: 411-412.

9 Patch C, Roderick P, Rosenberg W: Factors affecting the uptake of screening: a randomised controlled non-inferiority trial comparing a genotypic and phenotypic strategy for screening for haemochromatosis. J Hepatol 2005; 43: 149-155.

10 Delatycki MB, Allen KJ, Nisselle AE et al: Use of community genetic screening to prevent HFE-associated hereditary haemochromatosis. Lancet 2005; 366: 314-316.

11 Cadet E, Capron D, Gallet M et al: Reverse cascade screening of newborns for hereditary haemochromatosis: a model for other late onset diseases. J Med Genet 2005; 42: 390-395.

12 Gason AA, Aitken MA, Metcalfe SA, Allen KJ, Delatycki MB: Genetic susceptibility screening in schools: attitudes of the school community towards hereditary haemochromatosis. Clin Genet 2005; 67: 166-174.

13 Gason A, Sheffield E, Bankier A et al: Evaluation of a Tay-Sachs disease screening program. Clin Genet 2003; 63: 386-392.

14 Mitchell JJ, Capua A, Clow C, Scriver CR: Twenty-year outcome analysis of genetic screening programs for Tay-Sachs and beta-thalassemia disease carriers in high schools. Am J Hum Genet 1996; 59: 793-798.

15 Metcalfe SA, Aitken M, Gaff CL: The importance of program evaluation: how can it be applied to diverse genetics education settings? J Genet Couns 2008; 17: 170-179.

16 Delatycki MB, Wolthuizen M, Collins V et al: Implementation of ironXS: a study of the acceptability and feasibility of genetic screening for hereditary hemochromatosis in high schools. Clin Genet 2010; 77: 241-248.

17 Delatycki M, Allen K, Williamson R: Insurance agreement to facilitate genetic testing. Lancet 2002; 359: 1433.

18 Ware Jr JE, Sherbourne CD: The MOS 36-item short-form health survey (SF-36). I. Conceptual framework and item selection. Med Care 1992; 30: 473-483.
19 Marteau TM, Bekker H: The development of a six-item short-form of the state scale of the Spielberger State-Trait Anxiety Inventory (STAI). Br J Clin Psychol 1992; 31: 301-306.

20 Spielberger C, Gorusch R, Luchene R: State-Trait Anxiety Inventory: Manual. Consulting Psychologists Press: Palo Alto, 1983.

21 Melvin GA, Molloy GN: Some psychometric properties of the Positive and Negative Affect Schedule among Australian youth. Psychol Rep 2000; 86: 1209-1212.

22 Watson D, Clark LA, Tellegen A: Development and validation of brief measures of positive and negative affect: the PANAS scales. J Pers Soc Psychol 1988; 54: 1063-1070.

23 Horowitz M, Wilner N, Alvarez W: Impact of Event Scale: a measure of subjective stress. Psychosom Med 1979; 41: 209-218.

24 Gason AA, Metcalfe SA, Delatycki MB et al: Tay Sachs disease carrier screening in schools: educational alternatives and cheekbrush sampling. Genet Med 2005; 7 : 626-632.

25 Schmitt B, Golub RM, Green R: Screening primary care patients for hereditary hemochromatosis with transferrin saturation and serum ferritin level: systematic review for the American College of Physicians. Ann Intern Med 2005; 143 : 522-536.

26 Power TE, Adams PC, Barton JC et al: Psychosocial impact of genetic testing for hemochromatosis in the HEIRS Study: a comparison of participants recruited in Canada and in the United States. Genet Test 2007; 11: 55-64.

27 Wenzel LB, Anderson R, Tucker DC et al: Health-related quality of life in a racially diverse population screened for hemochromatosis: results from the Hemochromatosis and Iron Overload Screening (HEIRS) study. Genet Med 2007; 9: 705-712.

28 Patch C, Roderick P, Rosenberg W: Comparison of genotypic and phenotypic strategies for population screening in hemochromatosis: assessment of anxiety, depression, and perception of health. Genet Med 2005; 7: 550-556.

29 Power TE, Adams PC: Psychosocial impact of C282Y mutation testing for hemochromatosis. Genet Test 2001; 5: 107-110.

30 Nisselle AE, Collins VR, Gason AA et al: Educational outcomes of a workplace screening program for genetic susceptibility to hemochromatosis. Clin Genet 2006; 69: $163-170$.

31 Frumkin A, Zlotogora J: Genetic screening for reproductive purposes at school: is it a good strategy? Am J Med Genet A 2008; 146A: 264-269.

32 Allen K, Williamson R: Screening for hereditary haemochromatosis should be implemented now. BMJ 2000; 320: 183-184.

33 Haddow JE, Bradley LA: Hereditary haemochromatosis: to screen or not. Conditions for screening are not yet fulfilled. BMJ 1999; 319: 531-532.

34 Hall MA, Barton JC, Adams PC et al: Genetic screening for iron overload: No evidence of discrimination at 1 year. J Fam Pract 2007; 56: 829-834.

35 Smith CO, Lipe HP, Bird TD: Impact of presymptomatic genetic testing for hereditary ataxia and neuromuscular disorders. Arch Neurol 2004; 61: 875-880.

Supplementary Information accompanies the paper on European Journal of Human Genetics website (http://www.nature.com/ejhg) 